\title{
Physiotherapist involvement in the pandemic era: a Lombardy region survey
}

\author{
Emilia Privitera ${ }^{1,2}$, Francesco D’Abrosca ${ }^{2}$, Giuseppe Gaudiello², Marta Lazzeri' ${ }^{2,3}$, Angela Bellofiore ${ }^{1}$, \\ Pamela Frigerio $^{4}$, Martina Santambrogio ${ }^{2,5}$
}

${ }^{1}$ Health Professions Department Unit, Fondazione IRCCS Ca' Granda Ospedale Maggiore Policlinico, Milan; ${ }^{2}$ Italian Association of Respiratory Physiotherapists (ARIR); ${ }^{3}$ Cardio-Thoracic Department, ASST Grande Ospedale Metropolitano Niguarda, Milan; ${ }^{4}$ Mother-Child Department, ASST Grande Ospedale Metropolitano Niguarda, Milan; ${ }^{5}$ Respiratory Unit and Cystic Fibrosis Adult Center, Fondazione IRCCS Ca' Granda Ospedale Maggiore Policlinico, Milan, Italy

\begin{abstract}
In February 2020 the first COVID-19 case was reported in Italy and afterwards the virus started spreading rapidly, increasing dra-
\end{abstract}

\begin{abstract}
Correspondence: Emilia Privitera, PT, MSc, Dipartimento Professioni Sanitarie, Fondazione IRCCS Ca' Granda Ospedale Maggiore

Policlinico, Via Sforza 28, 20122 Milan,

Italy. Tel. +39.338.5670909. E-mail: emilia.privitera@policlinico.mi.it

Contributions: FD, GG, data acquisition; FD, GG, MS, data analysis; $\mathrm{EP}, \mathrm{FD}, \mathrm{GG}, \mathrm{AB}, \mathrm{MS}$ data interpretation, manuscript drafting; $\mathrm{EP}, \mathrm{FD}$, GG, AB, ML, PF, MS, manuscript critical revision for important intellectual content; EP, GG, AB, ML, PF, MS, conception and design of the work. All the authors have read and approved the final version of the manuscript and agreed to be accountable for all aspects of the work.
\end{abstract}

Conflict of interests: authors declare no conflict of interests.

Availability of data and material: The datasets used and/or analyzed during the current study are available from the corresponding author on reasonable request.

Funding: No funds for the present study

Prior abstract publication/presentation: No prior abstract publication and presentation of the present study.

Ethical approval and consent to participate: As it is a descriptive study, no IRB approval was requested. Consent form was signed by all participants. Data were collected and analysed only by researchers, providing full confidentiality and anonymity.

Acknowledgments: Authors would like to acknowledge the National Professional Order and its Lombardy region section that helped in developing and submitting this survey to all physiotherapists of the region. Moreover, authors would like to acknowledge Mattia

Mazzoleni for his help and support.

Received for publication: 5 Janaury 2021.

Accepted for publication: 17 April 2021.

${ }^{\circ}$ Copyright: the Author(s), 2021

Licensee PAGEPress, Italy

Monaldi Archives for Chest Disease 2021; 91:1762

doi: 10.4081/monaldi.2021.1762

This article is distributed under the terms of the Creative Commons Attribution Noncommercial License (by-nc 4.0) which permits any noncommercial use, distribution, and reproduction in any medium, provided the original author(s) and source are credited. matically the number of infected subjects. To face the pandemic outbreak, hospitals converted wards to assure COVID-19 patients' care and adopted measures to reduce virus diffusion. The aim of this study was to determine how many physiotherapists, in the Lombardy region, worked during pandemic, whether they continued their usual practice or were employed in COVID-19 wards and in which tasks they were involved. The survey was submitted online by the national professional order. The response rate was $11.79 \%$. During the pandemic, $648(53.9 \%)$ respondents interrupted their services. Less than $20 \%$ of the physiotherapists that continued working were assigned to COVID-19 wards with the role of physiotherapist. Only a small proportion of respondents had advanced skills in respiratory physiotherapy. Moreover, this study showed a limited involvement of physiotherapists inside the very acute and intense settings. In conclusion, this work revealed that, during COVID-19 pandemic, in the Lombardy region a small percentage of physiotherapists was employed in COVID-19 wards, mainly in post-acute context. Even though the response rate of this survey was very low, this study highlights the need to define and underline the role of physiotherapy in acute setting during emergency.

\section{Introduction}

The epidemic of severe acute respiratory syndrome coronavirus 2 (SARS-CoV-2) saw its peak between February and April 2020 in Italy. 254283 total cases were reported on August $18^{\text {th }}$ 2020. The trend of infections in Italy had a slow decrease of new cases until July and a continuous increase from October 2020 onwards. The Lombardy Region had the higher number of cases in Italy, with 106727 total cases and 16955 deaths recorded until October $1^{\text {st }} 2020$ [1].

In order to address the emergency, hospitals converted entire buildings and wards in semi-intensive and intensive care units and trained dedicated coronavirus disease 2019 (COVID-19) teams consisting of physicians, intensivists or pulmonologists or other trained specialists as well as infectious disease specialists and nurses $[1,2]$.

Following the critical illness, a certain amount of the subjects who survived the disease can present dyspnea and fatigue at rest and during activity of daily living (ADL), disability, exercise intolerance, reduction in peripheral muscle function and in nutritional status with significant weight loss $[3,4]$.

Respiratory and physical rehabilitation had a key role in this scenario both in acute and chronic settings. Rehabilitation clinics in fact, also dedicated wards and resources to COVID-19 treat- 
ment [2]. Physiotherapists are among the professionals involved in the management and care of this patient population and play a key role in every setting of rehabilitation, from hospital to home care. In addition, as a medical practice, physiotherapy has been ensured for not-COVID-19 acute and chronic conditions considered as urgent and non postponable.

During the emergency period, the Italian Association of Physiotherapy (AIFI) and the National Professional Order wrote and updated guidelines for physical therapy management, based on the recommendations given by the World Health Organization (WHO) and other national institutions, in order to keep the professionals and the patients safe and to reduce the spread of the infection $[2,5-7]$.

The recommendations promote shifting to video consultation when possible, triaging by phone in order to identify potential cases of infection, reorganizing the spaces and using personal protective equipment (PPE) [8,9].

Hence, rehabilitation experienced a dramatic change from an organizational point of view: some physiotherapists were recruited to deal with the health emergency, others instead suspended or changed part of their job activities.

In order to assess how the physiotherapists' job was affected in Lombardy Region, for both those involved in COVID-19 treatment and those not involved, a survey was conducted from the Italian Association of Respiratory Physiotherapists (ARIR), in collaboration with the National Professional Association (Associazione Italiana di Fisioterapia, AIFI). The purpose of this study was to investigate the reorganization of the work of physiotherapists during and after the peak period of the first pandemic wave. The primary outcome of this study was to understand how many physiotherapists worked with COVID-19 patients in Lombardy Region. Moreover data about organizational aspect (physiotherapy service change, potential duty changes), about the severity of COVID-19 patients treated by physiotherapists and about specific interventions delivered during pandemic were recorded.

\section{Methods}

\section{Study design and setting}

This study conforms to the Checklist for Reporting Results of Internet E-Surveys (CHERRIES) and reports the required information accordingly (Annex 1) [10].

All the physiotherapists registered to the regional Order of Lombardy at the time the survey was launched $(10,188$ physiotherapists), were invited to answer a survey about work organization during COVID-19 pandemic, submitting an online form.

Participants were reached through the mailing list of the regional professional association belonging to the Italian Professional Order. The survey investigated the work of physiotherapists during the first pandemic wave (from March $1^{\text {st }}$ until June $15^{\text {th }} 2020$ ). The survey was launched on May $2^{\text {nd }}$ and closed on August $15^{\text {th }} 2020$, and no reminders were send to the mailing list. No advertising of the survey was carried out. Data recorded were analyzed form August $15^{\text {th }}$ to October $15^{\text {th }}$. No incentives or prizes were offered. The survey was voluntary.

\section{Questionnaire}

This open survey was built by ARIR and AIFI. First, a review of the international literature about the topics included in the sur- vey was performed. Coronavirus disease clinical aspects, the physiotherapy treatments, the emergency protocols adopted by hospitals and professional studios were investigated. A panel of expert composed by physician and physiotherapists discussed about the aims and the topics of the survey, built the questionnaire and two external expert assessed content-related validity. 20 random physiotherapists tested the survey before submission and a second revision was performed before launching the survey.

The panel selected 2 main topics: organizational and clinical aspects. The survey contained 21 items, all close-ended questions of which 16 were multiple choice questions and 5 dichotomous questions. Preliminary questions about the geographical area and the type of workplace were asked (questions 1 and 2). The organizational aspects included questions about the conversion of wards, the potential duty changes and the COVID-19 team composition, where present (questions 3 to 14). The clinical topic was declined in 4 aspects: assessment (questions 15, 16 and 17), treatment (question 18), PPE management (question 19) and clinical and scientific research (questions 20 and 21).

The questionnaire was uploaded on Google Form platform (Annex 2). Google Forms did not record the I.P. address or the email of the form submitter. No personal data or unique visitor check systems were used. No view rate and timestamp were recorded.

The questionnaire included an introduction outlining the main study aims and the time required to complete the questionnaire (approximately 10 minutes), clarifying that participation was voluntary and assuring anonymity and confidentiality of information given (Annex 2).

No personal information or tracking systems were used. No identification data were required. All data collected were be processed and stored strictly anonymously pursuant to Legislative Decree 196/2003 and subsequent amendments and additions regarding the processing of personal data. By completing the questionnaire and submitting the answers, participants agreed to the collection, analysis and potential publication of data in an anonymous and aggregate form.

Respondents were allowed to review and change their answers before submit the questionnaire.

\section{Outcomes and procedures}

The primary outcome of this study was the number of physiotherapists that worked with COVID-19 patients in Lombardy Region during pandemic from March $1^{\text {st }}$ to June $15^{\text {th }}$. Secondary outcomes were the number of physiotherapists that changed their roles during pandemic, the number and type of hospital staff members involved in COVID-19 patients care, the severity of COVID-19 patients treated by physiotherapists and, eventually, which types of specific interventions were delivered during pandemic. Physiotherapists' formation, education and skills were also recorded.

\section{Sample size and data analysis}

Survey sample size was determined considering 95\% confidence interval and 3\% margin of error. The calculated sample size was 966 respondents [11].

Only completed questionnaires were included in the final dataset. For data analysis, open questions were classified and assigned to category according to a keyword clustering method. Data analysis was stratified by physiotherapists working and not working during pandemic, by physiotherapists working and not in COVID-19 wards, and by physiotherapists transferred in COVID19 wards and physiotherapists whose affiliation ward was convert- 
ed into a COVID-19 ward. Data analysis was performed with Microsoft Excel.

\section{Results}

\section{Geographic distribution, working structure, type of employment and expertise}

Of the 10188 questionnaires sent to the physiotherapists registered to the regional Order of Lombardy at the time the survey was launched, 1201 physiotherapists answered, with an $11.79 \%$ response rate.

Participants' geographic distribution, working structure, type of employment and expertise were reported in Table 1. A small proportion of participants $(56,4.7 \%)$ had advanced expertise in respiratory physiotherapy, being able to manage ventilators, while 634 (52.8\%) had basic knowledge. Physiotherapists with advanced and intermediate expertise in the respiratory field worked mainly in public or private research hospitals (Figure S1).

\section{Physiotherapists working during COVID-19 pandemic}

During COVID-19 pandemic, among overall respondents, 553 (46.0\%) physiotherapists constantly worked. Among the totality of respondents, $422(35.1 \%)$ worked as physiotherapists, while 131 $(10.9 \%)$ have been asked to support nurses in patients' assistance, also as auxiliary personnel (Table 2).

Among overall respondents, 233 (19.4\%) were assigned to COVID-19 wards with the role of physiotherapist, of which 95 $(40.8 \%)$ were transferred to a COVID-19 ward, while 138 (59.2\%) declared their working ward was converted into a COVID-19 ward and they have kept on doing their routinely work. Those working as physiotherapists in a COVID-19 ward represented $42.1 \%$ of the 553 active during pandemic (Table 2).

A small proportion of overall respondents was involved in the treatment of patients in intensive care unit (ICU; 79, 6.6\% of overall respondents; $34 \%$ of physiotherapists involved into COVID-19 wards), while a greater proportion in the management of patients post ICU discharge $(267,22.2 \%$ of overall respondents) or those with mild to moderate symptoms admitted to the general ward (290, $24.1 \%$ of overall respondents).

Among overall respondents, 648 (53.9\%) discontinued or did not work during COVID-19 pandemic. Reasons of not working are reported in Table 2 .

\section{Physiotherapy services changes}

In order to face COVID-19 burden, 671 (55.9\%) participants indicated changes in the organization of their physiotherapy service (Table 3). Among overall respondents, physiotherapy services were temporarily closed $(39,3.9 \%)$ and in few cases telerehabilitation programs were proposed $(8,0.7 \%)$ and remote working started $(2,0.2 \%)$. Instead, in COVID-19 wards day shifts were rescheduled to ensure the presence of physiotherapists and personal protection equipment (PPE) was adopted. Among the 95 respondents transferred in COVID-19 wards, 32 (33.7\%) worked from 8 am to $8 \mathrm{pm}, 20(21.1 \%)$ worked $7 / 7$ days, and in $26(27.4 \%)$ cases the number of physiotherapy staff increased; among the 142 respondents whose wards were converted in COVID-19 wards, 43 (30.1\%) worked from 8 am to 8 pm, $22(15.5 \%)$ worked $7 / 7$ days, and in $38(26.8 \%)$ cases the number of physiotherapy staff increased. In $734(61.1 \%)$ of overall respondents, 0 to $25 \%$ of the physiotherapy staff was dedicated to the treatment of COVID-19 patients and in $142(11.8 \%)$ of overall respondents 75 to $100 \%$ of the therapists was involved in the care of COVID-19 infected people (Figure S2).

\section{Multidisciplinary team}

Physiotherapists that treated COVID-19 patients, worked with nurses and physicians, such as physiatrists $(65.2 \%)$, general practitioners $(41.6 \%)$, internists $(52.5 \%)$ and pulmonologists $(50.6 \%)$. Other healthcare professionals involved in COVID-19 management are reported in Table S1. One-hundred sixty-five (13.7\%) of overall respondents worked also in the ICU, collaborating with intensivists, to ensure an early rehabilitation and support the weaning process. Among those who never worked ICU during the pandemic (378, $31.5 \%$ of overall respondents), 196 (51.9\%) had no-experience or a basic knowledge of specific respiratory interventions, while 54 $(14.2 \%)$ had intermediate and 18 (4.7\%) had advanced experience.

\section{COVID-19 patient assessment}

Considering all responders working as physiotherapists during the pandemic (422), in $80.1 \%$ of cases they directly assessed and treated patients. Among overall responders, 608 (50.6\%) declared a COVID-19 ward in their workplace, 178 (29.2\%) of them worked with a physiatrist and $100(16.4 \%)$ treated COVID-19 patients only after a physiatrist visit (mainly in private and public hospitals) (Figure 1).

COVID-19 patients' assessment was investigated; specific scales and measurements, such as vitals and arterial blood gas evaluation, dyspnea and independence in ADL assessment and muscle strength measurement were used, as reported in Table 4.

\section{COVID-19 patient treatment}

A large proportion of the physiotherapy interventions delivered to COVID-19 patients represented mobilization interventions as sitting out of bed $(465,84.1 \%)$, walking $(464,83.9 \%)$, standing (444, 80.1\%), endurance training $(422,76.3 \%)$ and sitting on the bedside $(380,68.7 \%)$, whereas less responders delivered evidence based respiratory physiotherapy interventions, such as weaning from mechanical ventilation procedures $(62,11.2 \%)$, tracheostomy tube management $(56,10.1 \%)$ and weaning $(50,9.0 \%)$, use of noninvasive ventilation (NIV) and continuous positive airway pressure $(72,13.0 \%)$ (Table 4). A comprehensive evidence-based intervention, from preventive mobilization to advanced respiratory strategies (pronation, tracheostomy management and use of NIV), was provided only by physiotherapists who had an advanced or intermediate experience in respiratory physiotherapy $(20.1 \%$ of the total respondents).

\section{PPE and training}

During the treatment of COVID-19 patients, physiotherapists had to wear specific PPE, as reported in Table S3.

Overall respondents found information and guidelines mainly online, visiting physiotherapists' association websites, reading scientific published literature and following a distance learning course provided by the Italian National Institute of Health immediately after the first COVID-19 cases were found in Italy (Figure S3).

\section{Discussion}

This survey, conducted among all physiotherapists working in Lombardy, highlights several critical issues concerning the 
Table 1.

Geographic distribution, working structure, type of employment and expertise of respondents. Setting and activities carried out in each working structure are listed below.

- Scientific Institute for research, Hospitalization and Healthcare: Public, acute and chronic care, in- and out-patient + research and teaching.

- Territorial social and health department: Public, acute and chronic care, in- and out-patient.

- Private healthcare facility: Private, acute and chronic care, in- and out-patient, plus research and teaching.

- Home care services: Private, home care.

- Owner of a private practice in-site: Private, out-patient.

- Assisted Health Residence: Public or private housing facility.

- Rehabilitation Institute: Public or private, in- and out-patient

- Physical Therapy Rehabilitation Center: Public or private, out-patient

- Sport Recreation Center: Public or private, sport-related.

- Multidisciplinary Home Care Services: Public, home care.

- PWD Day Healthcare Center: public or private, day-care.

- Coworker in a private practice in-site: Private, out-patient.

\begin{tabular}{|c|c|}
\hline Working district & $\mathrm{n}=1201$ \\
\hline Milano, n (\%) & $410(34.1)$ \\
\hline Varese, n (\%) & $181(15.1)$ \\
\hline Pavia, n (\%) & $127(10.6)$ \\
\hline Bergamo, n (\%) & $121(10.1)$ \\
\hline Monza Brianza, n (\%) & $86(7.2)$ \\
\hline Cremona, n (\%) & $74(6.2)$ \\
\hline Como, n (\%) & $72(6.0)$ \\
\hline Lecco, n (\%) & $47(3.9)$ \\
\hline Lodi, n (\%) & $39(3.2)$ \\
\hline Sondrio, n (\%) & $29(2.4)$ \\
\hline Brescia, n (\%) & $3(0.2)$ \\
\hline No answer, n (\%) & $12(1.0)$ \\
\hline \multicolumn{2}{|l|}{ Working structure } \\
\hline Private healthcare facility, n (\%) & $223(18.6)$ \\
\hline Territorial social and health department, $\mathrm{n}(\%)$ & $194(16.2)$ \\
\hline Assisted Health Residence, $\mathrm{n}(\%)$ & $192(16.0)$ \\
\hline Owner of a private practice, $\mathrm{n}(\%)$ & $144(12.0)$ \\
\hline Coworker in a private practice, $\mathrm{n}(\%)$ & $93(7.7)$ \\
\hline Scientific Institute for Research, Hospitalization and Healthcare, n (\%) & $84(7.0)$ \\
\hline Physical Therapy Rehabilitation Center, n (\%) & $83(6.9)$ \\
\hline Home Care Services, n (\%) & $83(6.9)$ \\
\hline Rehabilitation Institute, $\mathrm{n}(\%)$ & $48(4.0)$ \\
\hline Multidisciplinar Home Care Services, n (\%) & $28(2.3)$ \\
\hline PWD Day Healthcare Center, $\mathrm{n}(\%)$ & $10(0.8)$ \\
\hline Sport Recreation Center, n (\%) & $7(0.6)$ \\
\hline No answer, $\mathrm{n}(\%)$ & $12(1.0)$ \\
\hline \multicolumn{2}{|l|}{ Type of employment } \\
\hline Long-time employee, n (\%) & $638(53.1)$ \\
\hline Short-time employee, $\mathrm{n}(\%)$ & $42(3.5)$ \\
\hline VAT registered employee, $\mathrm{n}(\%)$ & $467(38.9)$ \\
\hline Both with a suited and free VAT private practice contract, $\mathrm{n}(\%)$ & $37(3.1)$ \\
\hline No contract (volunteer), n (\%) & $5(0.4)$ \\
\hline No answer, n (\%) & $12(1.0)$ \\
\hline \multicolumn{2}{|l|}{ Expertise in the respiratory field } \\
\hline Advanced, n (\%) & $56(4.7)$ \\
\hline Intermediate, $\mathrm{n}(\%)$ & $185(15.4)$ \\
\hline Basic, n (\%) & $634(52.8)$ \\
\hline No expertise, n (\%) & $326(27.1)$ \\
\hline
\end{tabular}

PWD, persons with disabilities; VAT, value-added tax. 
role of physiotherapists in the pandemic of COVID-19. It underlines a dramatic underestimation of the role of physiotherapists during the emergency weeks. All the health facilities, of course, chose to stop all outpatients and other non-critical rehabilitation activities, while transforming wards to accept COVID positive or COVID negative patients, but only few organizations included physiotherapists as "physiotherapists" in the acute care teams. Many participants did not work at all during the emergency, oth- ers were converted in auxiliary personnel to support nurses and patients' needs. These data suggest an alarming lack of awareness about the role of physiotherapy among managers and others allied healthcare professionals and, perhaps, also among physiotherapists. Physiotherapy is not only rehabilitation, indeed it includes also prevention, care and palliation in a wide range of conditions and settings. The pandemic highlighted the need for a cultural change in the health organizations to enhance reciprocal

Table 2. Working activities performed by respondents during pandemic.

\begin{tabular}{|c|c|c|c|}
\hline During COVID-19 pandemic & $\begin{array}{l}\text { n (\% of overall } \\
\text { respondents) }\end{array}$ & During COVID-19 pandemic & $\begin{array}{l}\text { ( } \% \text { of overall } \\
\text { respondents) }\end{array}$ \\
\hline PT continued working & $553(46.0)$ & $\begin{array}{l}\text { PT who suspended their work } \\
\text { (voluntary or not) }\end{array}$ & 498 (41.5) \\
\hline $\begin{array}{l}\text { PT transferred to a COVID-19 ward } \\
\text { from orthopedics ward to COVID-19 ward) }\end{array}$ & $95(7.9)$ & PT stayed at home on vacation or over & $130(10.8)$ \\
\hline $\begin{array}{l}\text { Working ward was converted into a COVID-19 ward } \\
\text { and PT have kept on doing his/her routinary work }\end{array}$ & $138(11.5)$ & $\begin{array}{l}\text { PT was fired (or suspended if VAT registered } \\
\text { employee) due to the suspension } \\
\text { of physiotherapic activities at his/her facility }\end{array}$ & $62(5.2)$ \\
\hline $\begin{array}{l}\text { PT kept on doing his/her routinary work } \\
\text { in a non-COVID-19 ward }\end{array}$ & $187(15.6)$ & PT suspended home care services by his/her self & $76(6.3)$ \\
\hline $\begin{array}{l}\text { PT had to change his/her work role (patient care, } \\
\text { support to other operators) }\end{array}$ & $131(10.9)$ & PT suspended services at his/her own private practice & $219(18.2)$ \\
\hline $\begin{array}{l}\text { PT established a VAT registered employee relationship } \\
\text { in a facility with COVID-19 patients, working as a physiotherapist }\end{array}$ & $1(0)$ & $\begin{array}{l}\text { PT suspended services at his/her own private practice } \\
\text { and volunteered at some field hospital or emergency facility }\end{array}$ & ity $7(0.6)$ \\
\hline PT was hired in a facility to deal with the emergency & $1(0)$ & PT did not work & $4(0.3)$ \\
\hline No answer & $12(1)$ & $\begin{array}{l}\text { Other (changing his/her role/working status } \\
\text { during pandemic) }\end{array}$ & $138(11.5)$ \\
\hline
\end{tabular}

COVID-19, coronavirus disease 2019; PT, physical therapist; VAT, value-added tax.

Table 3. Change in the organization of physiotherapists work group to deal with the COVID-19 emergency (multiple responses allowed).

\begin{tabular}{ll} 
Organizational changes in physiotherapy services & $n=1201$ \\
Change in day shifts, $\mathrm{n}(\%)$ & $194(16.2)$ \\
Increased number of working hours, $\mathrm{n}(\%)$ & $122(10.2)$ \\
\hline Increased number of physiotherapists dedicated to respiratory physiotherapy interventions, $\mathrm{n}(\%)$ & $117(9.7)$ \\
Physiotherapy service working 7/7 days, $\mathrm{n}(\%)$ & $99(8.2)$ \\
\hline Physiotherapists did to other tasks, $\mathrm{n}(\%)$ & $61(5.1)$ \\
Reduced number of working hours, $\mathrm{n}(\%)$ & $60(5.0)$ \\
\hline Interruption of physiotherapy activities, $\mathrm{n}(\%)$ & $47(3.9)$ \\
Holidays, $\mathrm{n}(\%)$ & $32(2.7)$ \\
\hline Rotation of therapists between COVID-19 and not COVID-19 wards, $\mathrm{n}(\%)$ & $28(2.3)$ \\
Use of PPE and change in ward access, $\mathrm{n}(\%)$ & $26(2.2)$ \\
\hline Flexible shifts, $\mathrm{n}(\%)$ & $17(1.4)$ \\
Lay-off, $\mathrm{n}(\%)$ & $11(0.9)$ \\
\hline Telerehabilitation program, $\mathrm{n}(\%)$ & $8(0.7)$ \\
6/6 days shift, $\mathrm{n}(\%)$ & $6(0.5)$ \\
\hline Smart working, $\mathrm{n}(\%)$ & $2(0.2)$ \\
Only not COVID-19 wards, $\mathrm{n}(\%)$ & $2(0.2)$ \\
\hline Other, $\mathrm{n}(\%)$ & $12(1.0)$ \\
No changes, $\mathrm{n}(\%)$ & $12(1.0)$ \\
\hline
\end{tabular}

COVID-19, coronavirus disease 2019; PPE, personal protection equipment. 
Table 4. Measures used for COVID-19 patients' assessment and physiotherapy techniques used to treat COVID-19 patients.

\begin{tabular}{|c|c|}
\hline Measures for assessment of patients & $\mathrm{n}=553$ \\
\hline SpO2, n (\%) & $484(87.5)$ \\
\hline HR, RR and BP, n (\%) & $378(68.5)$ \\
\hline Dyspnea scale (VAS, Borg), n (\%) & $261(47.2)$ \\
\hline Barthel Index & $222(40.1)$ \\
\hline Chest X-Ray, Chest US, n (\%) & $198(35.8)$ \\
\hline 6MWT, 1m-STST, n (\%) & $193(34.9)$ \\
\hline Chest physical examination, $\mathrm{n}(\%)$ & $151(27.3)$ \\
\hline Arterial Blood Gas Test, n (\%) & $139(25.1)$ \\
\hline Muscle Strength (MRC scale, Handgrip), n (\%) & $96(17.4)$ \\
\hline Tinetti Scale, n (\%) & $13(2.3)$ \\
\hline SPPB, n (\%) & $8(1.4)$ \\
\hline Barthel for dyspnea, n (\%) & $1(0.2)$ \\
\hline Any scale/measurement, n (\%) & $25(4.5)$ \\
\hline Physiotherapy interventions delivered & $\mathrm{n}=553$ \\
\hline Passive mobilization of sedated patients, n (\%) & $170(30.7)$ \\
\hline Passive mobilization of awake patients, n (\%) & $1(0.2)$ \\
\hline Callistenic exercises coordinated with breathing, n (\%) & $135(24.4)$ \\
\hline Endurance training, n (\%) & $422(76.3)$ \\
\hline Postural changes in sedated patients, $\mathrm{n}(\%)$ & $143(25.9)$ \\
\hline Postural changes in awake patients, $\mathrm{n}(\%)$ & $337(60.9)$ \\
\hline Pronation, n (\%) & $108(19.5)$ \\
\hline Sit on bedside, $\mathrm{n}(\%)$ & $380(68.7)$ \\
\hline Sit out of bed, n (\%) & $465(84.1)$ \\
\hline Standing, n (\%) & $444(80.1)$ \\
\hline Walking, n (\%) & $464(83.9)$ \\
\hline Favoring independence in ADL, $\mathrm{n}(\%)$ & $335(60.1)$ \\
\hline Education before discharge to home, $\mathrm{n}(\%)$ & $2(0.4)$ \\
\hline Contribution in defining time of hospital discharge, $\mathrm{n}(\%)$ & $1(0.2)$ \\
\hline $\begin{array}{l}\text { Identification of adequate setting to continue the } \\
\text { rehabilitation pathway, } \mathrm{n}(\%)\end{array}$ & $1(0.2)$ \\
\hline Management of oxygen supply at rest, $\mathrm{n}(\%)$ & $204(36.9)$ \\
\hline Management of oxygen supply during exercise, $\mathrm{n}(\%)$ & $208(37.6)$ \\
\hline Education to oxygen use, n (\%) & $1(0.2)$ \\
\hline Use of HFNC, n (\%) & $57(10.3)$ \\
\hline Management of NIV/CPAP, n (\%) & $72(13.0)$ \\
\hline Participating in IMV weaning, $\mathrm{n}(\%)$ & $62(11.2)$ \\
\hline Management of tracheostomy, n (\%) & $56(10.1)$ \\
\hline Participating in tracheostomy weaning, n (\%) & $50(9.0)$ \\
\hline Diaphragmatic breathing, n (\%) & $96(17.4)$ \\
\hline Relaxation exercises, n (\%) & $68(12.3)$ \\
\hline Use of volume-incentive spirometer ( Coach), n (\%) & $41(7.4)$ \\
\hline Use of flow-incentive spirometer ( Triflow), n (\%) & $24(4.3)$ \\
\hline Use of PEP devices, n (\%) & $35(6.3)$ \\
\hline Manual respiratory assistance, $\mathrm{n}(\%)$ & $45(8.1)$ \\
\hline Postural drainage of airway secretion, $\mathrm{n}(\%)$ & $71(12.8)$ \\
\hline Modified postural drainage, $\mathrm{n}(\%)$ & $15(2.7)$ \\
\hline Use of NIV/CPAP for airway clearance, $n$ (\%) & $64(11.6)$ \\
\hline Bronchoaspiration, n (\%) & $39(7.1)$ \\
\hline Use of cough machine, $\mathrm{n}(\%)$ & $20(3.6)$ \\
\hline Manual cough assistance, $n(\%)$ & $36(6.5)$ \\
\hline Air stacking, n (\%) & $7(1.3)$ \\
\hline Drainage of edema post CPAP, n (\%) & $1(0.2)$ \\
\hline \multicolumn{2}{|c|}{$\begin{array}{l}\text { 1m-STST, 1-minute sit-to stand test; 6MWT, 6-minutes walking test; ADL, activity of daily living; BP, blood } \\
\text { pressure; Chest-US, chest ultrasound; CPAP, continuous positive airway pressure; HFNC, high flow nasal } \\
\text { cannula; HR, heart rate; IIVV, invasive mechanical ventilation; MRC c cale, medical research council scale; } \\
\text { NIV, non-invasive ventilation; PEPP, positive expiriatory pressure; RR, respiratory rate; } \mathrm{SPPB} \text {, short physical } \\
\text { performance battery; VAS, visual analogic scale. }\end{array}$} \\
\hline
\end{tabular}

knowledge among professionals and to empower interdisciplinary collaboration. Even, a pressing change of paradigm is needed to balance the number of professionals and competencies into the teams according to the mission of each health facility, including specific requirements for the personal recruitment, reviewing the accreditation criteria for ICUs and other specialistic units, and rising the policy maker awareness.

The number of experienced respiratory physiotherapists (RPT) has been shown to be very low $(4.7 \%, 56)$ and distributed mainly in research institutes, public and accredited hospitals, in the areas of Milan, Varese and Pavia (48.2\%, 16.0\% and $14.3 \%$ respectively). Data show that only those who declare an advanced or intermediate experience in respiratory physiotherapy, offered a comprehensive evidence-based intervention, including advanced strategies such as, pronation, weaning procedures, use of NIV and tracheostomy management. Out of this experienced groups, a number of obsolete (diaphragmatic breathing, callisthenic exercises, postural drainage), or non-evidence-based therapies (cough augmentation techniques, incentive spirometry, relaxation exercises) were proposed [2,13-16]; a lack of specific respiratory interventions compared to more generic mobility interventions is also shown. In addition, only $6.6 \%$ of the overall respondents worked also in the ICU, to ensure early mobilization and to cooperate in the process of weaning from invasive mechanical ventilation.

This survey once again reveals the lack of culture of pulmonary rehabilitation and the importance of early respiratory physiotherapy. To answer the real needs of the population, we need to revise the physiotherapists' core curriculum in order to empower the cardio-respiratory competencies.

Also telerehabilitation has been used very little during the pandemic by the professionals interviewed, this can be due to deficiencies in the equipment needed. It will be interesting to investigate whether and to what extent the suspension of usual physiotherapy treatments during pandemic will impact not-COVID patients in terms of disability, functional recovery and quality of life.

Although the questionnaire was sent to all registered physiotherapists of our region, the response rate was very low, as respondents were volunteers. The low response rate represents the main limitation of this study, although similar rate of response is often found in the literature for e-surveys [12]. We think that these preliminary data could give interesting insights on what happened in the Lombardy region during the first COVID-19 pandemic wave. Moreover, the recruitment method used present a bias, as multiple responses could come from physiotherapists that work in the same workplace. The first overview on the geographical data shows a proportional coherence between the number of registered physiotherapists and response rate among different areas. Respondents were well balanced between those employed in public or accredited hospitals and public assistance and those working in community services or at home.

\section{Conclusions}

During COVID-19 pandemic, a small proportion of physiotherapists of the Lombardy region was employed in COVID-19 wards, mainly in post-acute care. Although limited by a low response rate, this work highlight a massive underestimation of the role of physiotherapy during the pandemic in the acute emergency setting. 


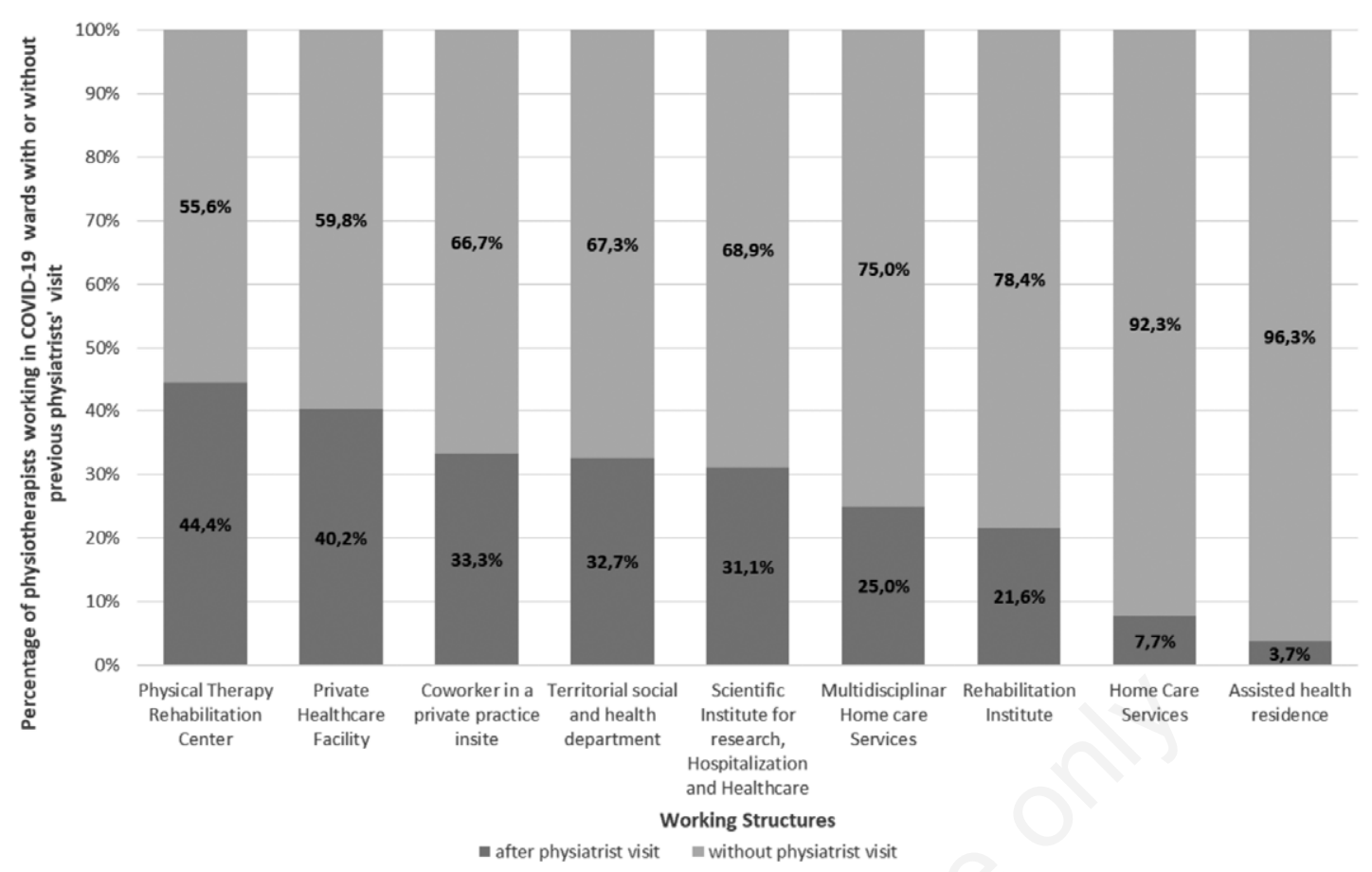

Figure 1. Percentage of physiotherapists that took charge of COVID-19 patients with or without a previous physiatrists' assessment.

\section{References}

1. Armocida B, Formenti B, Ussai S, et al. The Italian health system and the COVID-19 challenge. Lancet Public Health 2020;5:e253.

2. Lazzeri M, Lanza A, Bellini R, et al. Respiratory physiotherapy in patients with COVID-19 infection in acute setting: a Position Paper of the Italian Association of Respiratory Physiotherapists (ARIR). Monaldi Arch Chest Dis 2020;90: 1285.

3. Vitacca M, Lazzeri M, Guffanti E, et al. Italian suggestions for pulmonary rehabilitation in COVID-19 patients recovering from acute respiratory failure: results of a Delphi process. Monaldi Arch Chest Dis 2020;90:1444.

4. Belli S, Balbi B, Prince I, et al. Low physical functioning and impaired performance of activities of daily life in COVID-19 patients who survived hospitalisation. Eur Respir J 2020;56: 2002096.

5. Associazione Italiana Fisioterapisti AIFI, Commissioni di Albo dei Fisioterapisti. [Aggiornamento sulla nota sulla rimodulazione degli interventi fisioterapici nell'emergenza COVID19].[Report in Italian]. Available from: https://aifi. net/wpcontent/uploads/2020/04/Aggiornamento-rimodulazioneinterventi-FT-CDAFT-AIFIagg-20-02-2020-Finale.pdf

6. Associazione Italiana Fisioterapisti AIFI, Commissioni di Albo dei Fisioterapisti. [Nota su DPCM 26 April 2020].[Report in Italian]. Available from: https://aifi.net/wpcontent/uploads/ 2020/04/NOTA-SU-DPCM-26-04-20.pdf

7. Associazione Italiana Fisioterapisti AIFI, Commissioni di Albo dei Fisioterapisti. [Note sulla rimodulazione degli interventi fisioterapici in relazione all'emergenza COVID19].[Report in Italian]. Available from: https://aifi.net/wpcontent/uploads/
2020/05/Note-sulla-rimodulazione-degli-interventi-idrokinesiterapici-insetting-....pdf

8. World Health Organization. Clinical management of severe acute respiratory infection (SARI) when COVID-19 disease is suspected: interim guidance, 13 March 2020. Available from: https://apps.who.int/iris/handle/10665/331446

9. Associazione Italiana Fisioterapisti AIFI, Commissioni di Albo dei Fisioterapisti. [Emergenza sanitaria COVID 19. Suggerimenti operativi per i fisioterapisti].[Report in Italian]. Available from: https:/aifi.net/wp-content/uploads/2020/03/ suggerimenti-COVID19-per-fisioterapisti-congiunto-AIFICDA-OrdiniTSRMPSTRP-10-marzo-020-def.pdf

10. Eysenbach G. Improving the quality of Web surveys: the Checklist for Reporting Results of Internet E-Surveys (CHERRIES). J Med Internet Res 2004;6:e34.

11. Taherdoost H. Determining sample size; How to calculate survey sample size. Int J Econ Manage Syst 2017;2. Available from: https://ssrn.com/abstract=3224205

12. Baruch Y. Response rate in academic studies-A comparative analysis. Hum Relat 1999;52:421.

13. Gosselink RA, Wagenaar RC, Rijswijk H, et al. Diaphragmatic breathing reduces efficiency of breathing in patients with chronic obstructive pulmonary disease. Am J Respir Crit Care Med 1995;15:1136-42.

14. Fink JB. Positioning versus postural drainage. Respir Care 2002;47:769-77.

15. Lannefors L, Wollmer P. Mucus clearance with three chest physiotherapy regimes in cystic fibrosis: a comparison between postural drainage, PEP and physical exercise. Eur Respir J 1992;5:748-53.

16. Vitacca M, Clini E, Bianchi L, Ambrosino N. Acute effects of deep diaphragmatic breathing in COPD patients with chronic respiratory insufficiency. Eur Respir J 1998;11:408-15. 